\title{
"Consensus Building in Engagement Processes" for Reducing Risks in Developing Sustainable Pathways: Indigenous Interest as Core Elements of Engagement
}

\author{
Jenny Lieu, Luis D. Virla, Ryan Abel, and Cecilia Fitzpatrick
}

\begin{abstract}
Canada is one of the top ten greenhouse gas (GHG) emitters in the world, and of the nation's total, the province of Alberta was the biggest emitter primarily due to the fossil fuel industry and power generation. Alberta is currently facing a challenge to reduce GHG emissions in line with Canada's obligations to meet Paris Agreement goals. Additionally, the oil sand deposits in Alberta are located on the traditional land of Indigenous communities; therefore, the development, regulation and consultation of this sector have a direct impact not only on emissions but also on the socioeconomic welfare of Indigenous communities. Thus, the transition towards a low-carbon pathway in the oil sand industry is closely connected to upholding the rights of Indigenous peoples. Meaningfully consulting with Indigenous peoples is essential when developing low-carbon pathways that impact the environment and wellbeing of the community. Failure to consult proposed changes with Indigenous communities can lead to risks for the government, the industry and the communities themselves. These risks have been prevalent in the current consultation process in Alberta which has led to litigation, creating mistrust between the government, industry and Indigenous community. Given this background, we present a Consensus Building in Engagement Processes framework that includes Indigenous consensus, knowledge, interests and rights as a focal point of a consultation process required for decision-making. The consultation process is presented within the
\end{abstract}

\footnotetext{
J. Lieu $(\bowtie)$

Science Technology Policy Research Unit (SPRU), University of Sussex, Brighton, UK e-mail: J.Lieu@sussex.ac.uk
}

L. D. Virla

Department of Chemical and Petroleum Engineering, University of Calgary, Calgary, AB, Canada

R. Abel

Sustainability Department, Fort McKay First Nation, Wood Buffalo, AB, Canada

C. Fitzpatrick

Fort McKay First Nation, Wood Buffalo, AB, Canada

(C) The Author(s) 2019

H. Doukas et al. (eds.), Understanding Risks and Uncertainties in Energy and

Climate Policy, https://doi.org/10.1007/978-3-030-03152-7_2 
context of land use decisions impacting a low-carbon future for oil sand development. The framework is based on seeking consensus from all parties involved and aims to help to reduce risks resulting from decisions that do not consider the interests and rights of communities most impacted by resource development or climate mitigation pathways.

Keywords Sustainability $\cdot$ Indigenous knowledge $\cdot$ Consultation Engagement $\cdot$ Risk $\cdot$ Pathways

\section{Introduction}

The Paris Agreement, developed within the United Nations Framework Convention on Climate Change (UNFCCC), aims to reinforce the global action to the menace of climate change. The Agreement proposes a framework that integrates economy, policy, technology and society in order to keep global temperature rise in this century below $2{ }^{\circ} \mathrm{C}$ above pre-industrial levels (UNFCCC 2017). Due to its geographic location and landscape, Canada faces challenges when addressing climate change. Extreme temperatures, vast land mass, growing population, a diversified growing economy and abundant natural resources are some of the factors impacting GHG emissions in Canada (UNFCCC 2015). By 2014, Canada's total GHG emissions ascended to 732 megatonnes (Mt) $\mathrm{CO} 2$ equivalent, excluding land use, land use change and forestry estimates.

Canada contributes $1.6 \%$ of global emissions and is one of the top ten emitters (both total and per capita) in the world (World Resources Institute 2016). Fossil fuel production corresponded to the biggest contributors to this total, comprising $27 \%$ of total emissions in Canada (Natural Resources Canada 2016). Of the nation's total, the province of Alberta contributed 37.4\% in 2014, representing the biggest emitter among all provinces in Canada (Natural Resources Canada 2016). The total per capital emissions in Alberta amounted to 66.6 tonne per capita in 2013, compared to the country average of 20.7 tonne per capita, and are expected to increase further if no measures are taken (Boothe and Boudreault 2016). The close relationship of Alberta with the fossil fuel industry sector and power generation has steadily increased emissions. The oil and gas sector contributed to $39.4 \%$ of the GHG emissions in the overall Albertan economy in 1990 and has increased to $48.3 \%$ in 2015 (Environment Canada 2017).

As part of the Paris Agreement, in 2016 Canada agreed to decrease GHG emission by $30 \%$ below 2005 levels by 2030 . The mechanism in place to achieve this goal mainly involves the development of regulatory measures, such as changes in the transportation and electricity sectors, controlling landfill emissions and promoting clean energy technologies. Specifically for the province of Alberta, policies around carbon pricing, emission capping, electricity generation from renewables and increased efficiency in energy usage have been developed to decrease emission 
growth and maintain similar levels of today (Leach et al. 2015). Prior to the Paris Agreement in 2015, the Government of Alberta released a Climate Leadership Plan for the province which proposed emission caps, an emission trading system and a carbon tax for facilities that exceed the 100,000 CO2 tonnes/year. The Plan set grounds for the Oil Sands Emissions Limit Act, which created a legal obligation for the oil sand sector to limit emissions to $100 \mathrm{Mt}$ per year (Leach et al. 2015). To guarantee the implementation and acceptance of those policies, the concerns of stakeholders including industry, government and society must be properly addressed.

The oil sand deposits in Alberta-the world's third-largest proven oil reserves (Energy Resources Conservation Board 2010)_are located on traditional land of approximately 24 Indigenous $^{1}$ communities. For example, the Athabasca region in Alberta overlaps with traditional territories of five Indigenous communities distributed across the Regional Municipality of Wood Buffalo (RMWB): Mikisew Cree First Nation, Athabasca Chipewyan First Nation, Fort McKay First Nation, Fort McMurray No. 468 First Nation and Chipewyan Prairie Dene First Nation. Therefore, the development, regulation and consultation of this sector have a direct impact not only on the environment but also on the socioeconomic welfare of these communities.

Currently, the low-carbon emission pathway is defined at the national and provincial levels in terms of emission reductions. The details of how the low-carbon pathway will be implemented in the oil sand sector are currently being defined. An important factor to consider in a low-carbon future for Alberta is the inclusion of interests and needs of Indigenous communities affected by oil sand development. Indigenous communities must be consulted in the development of a pathway that could significantly impact their future. In fact, the Paris Agreement stipulates that when addressing climate change, all nations in the Paris Agreement are expected to "respect, promote and consider their respective obligations on human rights; the right to health; the rights of Indigenous peoples, local communities, migrants, children, persons with disabilities and people in vulnerable situations; and the right to development, as well as gender equality, empowerment of women and intergenerational equity" (UNFCCC 2017, p. 21).

Studying the rights and interests of the Indigenous population in the context of Canada is important from a sustainability and climate justice perspective. The Alberta government's policy agenda of transitioning towards a low-carbon pathway in the oil sand sector-100 Mt of CO2 cap (Leach et al. 2015)—cannot be disconnected from the rights of the Indigenous people who reside on the lands where oil sands are extracted. Thus, we argue that, when Indigenous rights and values are protected, the lands and the environment overall are also protected, and this supports

\footnotetext{
${ }^{1}$ Within the Canadian contexts, Indigenous peoples are referred to First Nations, Aboriginal peoples, Indigenous and Native. When discussing constitutional rights, the term "Aboriginal peoples" is used, while other terms are used interchangeably in literature (University of Alberta 2015).
} 
pathways to a low-carbon future (Baker 2013). Therefore, developing a fair consultation process that fully includes Indigenous rights and interests can help contribute towards a more sustainable low-carbon economy.

This chapter presents a framework that includes Indigenous knowledge, interests and rights as a focal point of a consultation process required for decision-making. This framework is based on discussions and interviews with Indigenous community members, industry, academics and government representation over the period of 2016-2017. ${ }^{2}$ The consultation process is presented within the context of land use decisions impacting a low-carbon future for oil sand development in Alberta. The consultation involves three major groups including Indigenous communities, industry and government. This chapter will also explore risks in the current resource development consultation process. We define "risk" as barriers to effective consultation or as negative outcomes/impacts that may result from the consultation process being one-sided. For instance, exploring the negative outcomes of land use decisions is crucial, as decisions to develop the oil sands not only increase emissions (and reduce the ability of forests to take up atmospheric carbon due to deforestation in the boreal forest to make way for large projects) but also significantly impact the ability of Indigenous communities to exercise their Aboriginal and Treaty rights and practise their traditional way of life to which Canada has already formally committed.

This chapter is organised into seven sections. The first section begins by presenting an overview of studies that link the Indigenous knowledge and climate change. The next part provides a starting ground for understanding inclusion by recognising Indigenous rights to free, prior and informed consent in consultation. This leads to the third section where we provide a broad perspective of Indigenous rights and consultation in the Canadian context. In the fourth section, we identify risks in the current consultation process in Alberta. We then introduce Indigenous ways of knowing in part 5 and attempt to recentre the focus of consultation on the Indigenous values of respect, relevance, reciprocity and responsibility. This sets the stage for Sect. 6 where we introduce the framing for consensus building in consultation processes, which can be applied to developing future sustainable pathways (or to address broader resource development activities). In the final section, we provide a summary and suggest steps forward to applying the framing.

\footnotetext{
${ }^{2}$ List interviewees: Interview 1, academic (A1); Interview 2, academic (A2); Interview 3, Indigenous community member (CM1); Interview 4, Indigenous community member (CM2); Interview 5, Indigenous community member (CM3); Interview 6, expert (E1); Interview 7, expert (E2); Interview 8, Indigenous member (IM1); Interview 9, industry player (IP1); Interview 10, industry player (IP2); Interview 11, industry player (IP3); Interview 12, industry player (IP4); Interview 13 , industry player (IP5); Interview 14, non-for-profit organisation (NP1); Interview 15, policymaker (PM1). This case study is part of a wider EU Horizon 2020-funded project, TRANSrisk (Transition Pathways and Risk Analysis for Climate Change Policies); see http:// transrisk-project.eu/.
} 


\section{Previous and Current Studies Integrating Indigenous Knowledge and Climate Change}

There has been a wider acknowledgement on the role of Indigenous knowledge and addressing climate mitigation and adaptation respectfully. The dialogue between Western scientific studies and traditional ecological knowledge (TEK) is still relatively new. TEK is a branch of Indigenous knowledge, practices and beliefs that is passed down over generations on the relationship between living beings and the environment and provides valuable knowledge on addressing climate change (see Lertzman 2010, Berkes 1999, Huntington 1992, Albert 2001, Fox 2003, Brewster 2004, Eloka 2010, qtd. in Alexander et al. 2011). TEK is still a largely untapped resource and can significantly contribute to addressing climate change issues (Alexander et al. 2011).

One starting point for creating links can be the use of narratives in a collaborative relationship, sharing TEK and Western scientific findings on climate change. Examples include the international Indigenous Conference Snowchange organised in 2005. All members of circumpolar nations and Indigenous peoples met in the conference to discuss and share their observations (through narratives) and presented recommendation and actions forward to address climate change. The collaboration was built on sharing knowledge and gaining consensus on the issues related to the northern regions (Mustonen 2005).

Another example of collaboration between TEK and Western science is seen in the Fort McKay Berry Focus Group. This group, formed from members of the Fort McKay First Nation and scientists from the Wood Buffalo Environmental Association (WBEA), has developed a community-based programme for monitoring traditionally consumed berries in the area. The key elements on this project have been the development of a scientific methodology sensitive to the culture and tradition of the community members (Wood Buffalo Environmental Association 2017). Since 2010, this group has been successful in monitoring the health and quality of the berries, as well as important factors that impact these indicators. Beyond the results, the group has allowed the community stakeholders to more accurately inform environmental decisions (Wood Buffalo Environmental Association 2010).

The Arctic Climate Impact Assessment (ACIA) is another study of the Arctic regions carried over the span of 5 years with contributions from over 300 scientists and other experts and members of Indigenous communities. The study was the first comprehensive, integrated assessment of climate change and UV radiation over the Arctic regions that applied several climate models and was complemented with Indigenous knowledge (Symon et al. 2005).

Another example at global study that integrates Indigenous knowledge in addressing climate changes is seen in a panel session at the 2008 conference on Sustaining Cultural and Biological Diversity in a Rapidly Changing World: Lessons for Global Policy (AMNH 2008). The panel, comprising of Indigenous leaders and scholars in the area, compiled 57 Indigenous narratives from all over the world 
describing climate change and its impacts. The narratives provided valuable information over an extended period of time that was not captured in scientific records.

While studies about the inclusion of TEK are growing and there are more empirical studies on monitoring climate change, few studies have provided methods or tools that place Indigenous knowledge and interests as a starting point in developing climate change mitigation and adaptation action. In fact, the Western perspective of sustainability tends to be the dominating narrative both in a global context and in the Canadian context (Dearden and Mitchell 1998; Draper 1998 qtd. in McGregor and Debroah 2004). Authoritative climate change knowledge is institutionalised through the Intergovernmental Panel on Climate Change (IPCC) in such a way that promotes the "privileging of positivist science and technocratic perspectives, and the marginalisation of other ways of knowing (for example, local, traditional and Indigenous knowledge) ..." (Ford et al. 2016, p. 349). In other words, Indigenous knowledge would typically contribute to the dominating Western perspectives and play a secondary role in contributing to understanding climate change rather than respecting differing perspective of understanding and addressing climate change issues.

The Western narratives can also take on a colonising tone and can especially dominate in the area of resource management projects, which have significant environmental, cultural and socioeconomic impacts. Some studies have explored the ethical approaches for resource extraction and Indigenous peoples (Lertzman and Vredenburg 2015), but much more needs to be done to better reflect the voices and interests of Indigenous peoples. This imbalanced perspective calls for the implementation of a flexible methodology for consultation in issues that impact Indigenous peoples. A new collaboration is needed that considers the wide range of interests of Indigenous peoples while ensuring integration and free, prior and informed consent (FPIC) of Indigenous communities to develop low-carbon pathways capable of meeting the needs of the local, national and global interests.

\section{Inclusion of Indigenous Interests: Free, Prior and Informed Consent}

Before entering in the discussion about the consultation process in resource development in the Canadian context, we consider it relevant to clarify the concepts of consultation and free, prior and informed consent (FPIC) used for this work.

According to the Oxford dictionary, consultation can be defined as:

"The action or process of formally consulting or discussing" and can include "a meeting with an expert [...] in order to seek advice".

The discussion implies an exchange of information from an expert group. Indigenous communities are the experts in identifying the changes and impacts of activities performed in their lands, since they hold observation records for generations. Seeking advice requires a flow from knowledge from the expert group to the 
group who receives the knowledge. This knowledge flow in the consultation process, if not carefully implemented, can reinforce negative power structures if information is not respected and reciprocated by non-Indigenous parties.

The term free, prior and informed consent (FPIC) is a well-established concept in international human rights law affirmed in the United Nations Declaration on the Rights of Indigenous Peoples (UNDRIP). The term consent is defined in the Oxford dictionary as: "Permission for something to happen or agreement to do something". In order for this process of agreement to incorporate the FPI elements, the UN Office of the High Commissioner for Human Rights has established the following conditions (Pillay 2013):

Free, implies that there is no coercion, intimidation or manipulation; Prior, implies that consent is to be sought sufficiently in advance of any authorisation or commencement of activities and respect is shown to time requirements of Indigenous consultation/consensus processes; and Informed, implies that information is provided that covers a range of aspects, including the nature, size, pace, reversibility and scope of any proposed project or activity; the purpose of the project as well as its duration; locality and areas affected; a preliminary assessment of the likely economic, social, cultural and environmental impact, including potential risks [...]. (Pillay 2013, p. 2)

Obtaining FPIC can reduce the risks associated with large development projects. However, obtaining consent in itself is not sufficient and needs to be accompanied with a mutual understanding of what constitutes consent (see Baker 2013, p. 30).

\section{Indigenous Legal Rights and Consultation Process in Canada}

Government-Indigenous relations in Canada were initially formalised in the eighteenth century in the form of accords between the Crown and Indigenous communities. These accords, known as treaties, outline the terms for land distribution and were used to create peace between Indigenous people and settlers. Nearly $50 \%$ of the Canadian land mass is covered under these treaties, which include 59\% of the total Indigenous communities in the country (Indigenous and Northern Affairs 2008). Indigenous communities in the Athabasca region are included on Treaty Eight, which was signed in 1899 and has been submitted to include more communities. The terms of this treaty established reserves; annuities; hunting, trapping and fishing rights; agricultural aids; and other benefits for the Indigenous communities in exchange for the surrender of the land to the Crown (federal government) (Daniel et al. 1980). The implementation of the terms and conditions of Treaty Eight has been historically linked to misinterpretation and disagreements, since its creation responded mainly to economic considerations from the government instead of humanitarian concerns for the Indigenous communities. Today, the Athabasca region is rich in natural resources, and the increasing industrial activity in the area has raised pressure on the federal government to reassess the Treaty Eight terms and clarify the treaty by considering contemporary legal and political realities (Indigenous and Northern Affairs 2009). 
As established in Section 35 of the Constitution Act (1982), the Government of Canada is required to guarantee proper consultation of Aboriginal peoples and to accommodate Indigenous interests when the Crown contemplates action(s) that may negatively impact potential or established Aboriginal or Treaty rights (Government of Canada 1982). The element of accommodation has been reinforced in a number of important Supreme Court decisions over the past decades (1973-2014) (see Joseph 2017 for overview). The court cases have not only upheld Indigenous land rights and interests but emphasised the importance of the duty of the government to consult and accommodate Indigenous interests through negotiation rather than through litigation. These court cases present potential risk for the oil sand industry and also called for further government obligation to properly consult not only to satisfy legal obligations but to reach consensus.

Previous government consultation and accommodation processes have also been outlined in the Aboriginal Consultation and Accommodation, Updated Guidelines for Federal Officials to Fulfil the Duty to Consult (Indigenous and Northern Affairs 2011). The guidelines emphasise the need to consult and accommodate by providing "policy-based guidance to assist officials in their efforts to effectively incorporate consultations and, where appropriate, accommodation into government activities and processes" (Government of Alberta 2013, 2016a). The Guiding Principles and Consultation Directives were developed from lessons learnt through court cases and other best practice and engagement experiences. However, accommodation does not imply "consent". In fact, the term "consent" only appears once in the updated guidance as a reference to the United Nations Declaration on the Rights of Indigenous Peoples.

Although Canada has issued a Statement of Support to endorse the UN Declaration, the government has expressed concern with the interpretation of free, prior and informed consent (FPIC), which can imply the power of veto (United Nations 2008; Indigenous and Northern Affairs 2011). In 2014, the UN Special Rapporteur noted the importance of developing a policy framework for implementing the duty to consult with a genuine opportunity for Indigenous peoples to provide input and involvement through FPIC in early stages of project developments. Moreover, the Rapporteur emphasised that conducting consultation in "good faith" should not be regarded as granting "veto power". Instead, performing consultation in the aim of achieving consent implies meaningful and informed dialogue and accommodation (TORYS 2016). Echoing these concerns, the Truth and Reconciliation Commission of Canada in 2015 called on the corporate sector in Canada to adopt the United Nations Declaration on the Rights of Indigenous Peoples and commit to meaningful consultation, building respectful relationships and obtaining the free, prior and informed consent of Indigenous peoples before proceeding with economic development projects (Truth and Reconciliation Commission 2015).

With the (inter)national context as their backdrop, in February 2018, the Government of Canada proposed legal requirements in Bill C69 that requires full impact assessments of economic development projects. Certain listed projects are obliged to carry out impact assessments that consider impacts on the environment, health, society and the economy. Previously, social and economic impacts were broadly 
considered under environmental impact assessments. The bill "prohibits proponents" or companies "from carrying out a designated project if the designated project is likely to cause certain environmental, health, social or economic effects" (Minister of Environment and Climate Change, p. ii). However, the Government can still override the decision if the project is in the public interest but must "tak[e] into account the impacts on the rights of the Indigenous peoples of Canada, [and] all effects that may be caused by the carrying out of the project". The new bill also established the Impact Assessment Agency, who is obliged to form research and advisory committees that include "the interests and concerns of Indigenous peoples of Canada, and appoint as a member of any such bodies" (Minister of Environment and Climate Change, p. 78).

\section{Risks Identified in the Current Consultation Process Within the Canadian Context}

Considering the 1982 Constitution, Supreme Court cases and Federal Guidance and the Impact Assessment Act that recognises Indigenous rights, interests and the legal obligation to consult and accommodate, we argue for there is an urgent need to focus on both consultation and inclusion in the engagement process. Free, prior and informed consent can be gained through consultation and inclusion of Indigenous knowledge and interests in engagement processes, leading to decisions that accommodate Indigenous needs and rights. Protecting Indigenous rights and respecting their world views will also help Canada achieve the aims of the Paris Agreement.

In this section, we will identify current issues in the consultation process that leads to risk for the government, Indigenous community and industry.

\subsection{Government Aspect}

The Government of Canada has a legal responsibility to ensure that Indigenous rights (both constitutionally enshrined and those protected in treaty agreements) and interests are upheld. Government is responsible for establishing the consultation system and setting policies and legislative requirements, and importantly, they hold treaty agreements with many Indigenous communities. Within the context of Alberta, the initial energy resource lease is granted by the Alberta government (Alberta Energy) within a particular jurisdiction without needing to consult Indigenous communities, thus setting up an immediate likelihood for conflict in many situations, especially if those areas are culturally significant for an Indigenous community. Energy leases are granted to the proponent, and this then creates a legal expectation by the proponent that they will have the right to develop the resource, provided their project meets environmental impact assessment and other 
regulatory standards. Although the government formally advocates for consultation (through pressures from the legal system), the government bypasses direct consultation with communities. However, there are regulatory requirements for proponents to carry out consultation about their project(s). Thus, when the consultation process is officially initiated, proponents are often met with resistance. Proponents have effectively become the direct interface to address Alberta's desire to develop the oil sand resource and its associated decision-making and policies, which may conflict with Indigenous community interests. It is the current system itself that leads to increasing risks within the consultation process (Interview, E1, 2017).

The government has been criticised by both Indigenous communities and industry for playing a role that can interfere with meaningful consultation (Interviews, IP1-5, 2016-2017). They do not take part in the consultation process, but are responsible for assessing if there has been sufficient "communication" between the Indigenous community and the proponent. Yet the government does not ensure that the issues raised by Indigenous communities are accommodated or addressed. The Alberta government appears to oversee the process by reviewing consultation records in what seems to be an exercise to ensure legal risk has been minimised when project approvals are granted. It should be noted that First Nation communities in Alberta do not support the province's consultation policy (Interview, E1, 2017). At the project approval stage, governments and their regulatory agencies (e.g. Aboriginal Consultation Office of Alberta, ACO) do not necessarily apply conditions to the project that protect the communities' interests and address the concerns raised during consultation. Rather the consultation processes are assessed as a process rather than as a contribution to the final outcome.

The government can in fact reduce their own risk of litigation by not being directly involved in the consultation process. But there is a trade-off associated with the government's risk-averse behaviour. While the government reduces its own risk, the risk increases for other parties. For the proponents, the risk may involve significant delays and exploratory access to the land revoked due to litigation. For the Indigenous community, if the project is approved without meaningfully addressing the risky negative impacts to the environment, culture and community, they can take the proponent to court, leading to project delays or halting the project altogether. This requires resources from the community, and there may also be risks that the court decisions may not favour the community interests.

An example of litigation resulting from a lack of inclusion and consensus is seen in the case of an in situ oil sand development near the Fort McKay First Nation's Moose Lake reserves. The community of Fort McKay filed a lawsuit in 2016 against the province of Alberta to challenge the decisions passed by the province's Aboriginal Consultation Office (ACO), who granted consultation adequacy on the proposed development in Fort McKay's treaty land. The ACO's decision was a procedural clearance that allowed the Alberta Energy Regulator (AER) to approve the project. The community stated that the cumulative impacts (among other facts) of the development violated Fort McKay's Treaty rights. The ACO claimed that they were only permitted to consider site-specific impacts related to the development's direct impacts (Henton 2016; Weber 2016). The lack of meaningful consideration of 
the community's concerns and stated resultant impacts in the consultation process not only put the proposed project at risk but also eroded trust in the consultation process. Consultation may be a good starting point for discussion, but on its own does not imply an equal opportunity to exchange knowledge and interests if all parties concerned are not included as part of the decision-making process.

\subsection{Indigenous Aspect}

Currently Indigenous communities are over-consulted due to traditional land use research and the legal obligations for consultation (i.e. guidelines discussed above) introduced by provincial and federal governments (Interviews, CM1-3, 2016-2017). Particular members of the community including elders are frequently invited to consultation meetings, but their inputs are often not included to influence outcomes (Baker and Westman 2018). As a result, elders experience fatigue and are weary of consultation as the project often goes ahead regardless of their inputs and subsequently choose not to participate, thereby perpetuating the misconception of assimilation (King 2012, Simpson 2007 qtd. in Baker and Westman 2018). The needs and concerns of the community can sometimes be in conflict with the development, which can threaten a community's way of life and negatively impact the environment and their culture. Therefore, when Indigenous communities' views are not appropriately addressed and accommodated, there is a higher risk that the project will not effectively consider the long-term environmental and social impact (Baker 2013).

\subsection{Industry Aspect}

Consultation becomes a bureaucratic process for projects that require traditional land use assessment and where results assert that projects have no substantial impacts on the land. From the business perspective, the consultation obligation is viewed as a cumbersome bureaucratic process that prolongs business decisions and that do not necessarily benefit participants, including Indigenous right holders (Calgary Chamber 2015). Increasing approval times creates costs and financial risks, and the consultation process itself may lead to a negative outcome that places the entire project at risk. In order to satisfy the legal requirement, proponents must demonstrate that they have communicated with the Indigenous community. Proponents secure participation in the consultation process by paying an honorarium to community members when they attend meetings and share their traditional knowledge with a project proponent (Interviews, IP1-5 and E1, 2016-2017). However, consultation alone does not guarantee that the outcomes truly accommodate Indigenous interests and needs. In fact, consultation without inclusion of interests and needs reduces the ability of Indigenous right holders to influence outcomes in the consultation process, thus creating false hope and increasing the likelihood for litigation. 


\subsection{Who Bears the Responsibility?}

Even if Indigenous interests are included in the decision-making process, without consensus during this process, the accommodation of interest does not guarantee that Indigenous concerns are sufficiently addressed. In fact, the "First Nations Consultation \& Accommodation Handbook" states that "The Crown is ultimately responsible for accommodation, but project proponents may have a role in accommodating First Nations" (Laidlaw and Passelac-Ross 2014, p. 70). Therefore, the accommodation actions that directly or indirectly affect the socioeconomic welfare of the community rely on external parties that base their decision on a different set of values than those of the affected community. Without a common consensus of views, the accommodation process (if it exists at all) is likely to overlook the main needs of the community.

This takes us to the concept of "inclusion", where Indigenous rights, interests and knowledge are included in every step of the engagement and decision-making process in order to develop consensus. We define inclusion within the context of the engagement process as consciously incorporating Indigenous views, interests, rights and knowledge as a part of the outcomes in a decision-making process. The outcome is therefore built on consensus and reflects free, prior and informed consent.

\section{Understanding Indigenous Ways of Knowing and World Views as Essential Step Towards Inclusion}

Effective inclusion throughout the consultation process can help to build consensus and requires a number of considerations including learning and respecting Indigenous knowledge systems embedded in world views, engaging in effective listening, creating respectful spaces for conversation and reciprocating.

Acknowledging that Indigenous knowledge differs from Western knowledge can provide a starting point to effective consultation and inclusion. This involves understanding the fundamental principles of Indigenous knowledge, which stems from relational knowing based on inner metaphysical knowledge and the outer physical environment (Ermine 2000; Kovach 2010). In other words, Indigenous knowledge can be explained as "the peoples' cognitive and wise legacy as a result of their interaction with nature in a common territory" (Maurial 1999 p. 62, qtd. in Hart 2010).

Simpson (2000) identifies seven main Indigenous world views. The first recognises that "knowledge is holistic, cyclic, and dependent upon relationships and connections to living and non-living beings and entities" (Simpson 2000, p. 62). The second accepts that there are many truths that vary according to individual experiences. The third acknowledges that everything is alive, while the fourth emphasises that all things are equal. The fifth views the land as sacred, and the sixth recognises the importance of the relationship between people and the spiritual 
world. The last considers humans as the least important in this world (Simpson 2000 qtd. in Hart 2010).

A number of the Indigenous world views emphasise a strong relationship with the environment and are, in fact, more aligned to climate justice, sustainability and a low-carbon future compared to modern economic Western paradigms that promote economic growth as a core element of societal development.

The inclusion of Indigenous knowledge and interests (e.g. in building consensus for addressing resource developments or addressing sustainability) requires putting aside the colonial perspective that Western knowledge is the basis of understanding. Rather, the starting point of inclusion can begin by what Kirkness and Barnhardt (1991) describe as the 4Rs of respect, relevance, reciprocity and responsibility. The 4Rs emerged as a means of promoting a more effective "two-way exchange" between universities and Indigenous students who must enter into post-secondary institutions and adapt to a very different context and notion of hierarchy.

In the context of Canada, Indigenous communities have been making significant efforts to learn and adapt to the Western institutions and values in order to effectively communicate with the government and decision-making bodies; yet non-Indigenous Canadians have not learnt to reciprocate in conversing with Indigenous communities as whole (Harrington 1991 qtd. in Kirkness and Barnhardt 1991). Therefore, considering the $4 \mathrm{Rs}$ when engaging with Indigenous communities may help to bridge the communication and learning gap.

\subsection{Respect}

The first step for inclusion is "respecting" Indigenous culture. The meaning and value of Indigenous knowledge are embedded in its cultural context and present in everyday activities and life experiences (Kirkness and Barnhardt 1991). There should also be a recognition on how Western education imposed literacy, language, values and perspectives on generations of Indigenous peoples (Scollon and Scollon 1981), and how Indigenous communities survived colonisation. On the other hand, non-Indigenous approaches often take a less respectful position when addressing Indigenous communities. Indigenous peoples are approached and frequently asked to comment on existing agenda topics as opposed to being asked to share their own story (Archibald 2008). One means of avoiding a knowledge colonisation is to respectfully approach Indigenous communities without preconceived notions and to listen to their individual perspectives.

\subsection{Relevant}

Another starting point is to address issues that are "relevant" to Indigenous perspectives and experience as a legitimate source of knowledge. The Western perspective 
of "objectivity" and evidence-based facts "make oral histories suspect and unreliable" in the Canadian legal system, which is based on Eurocentric perspective that provides little space for diverging cultural world view (Pryce 1992, 35 qtd. in Archibald 2008, p. 106). The Western Canadian justice systems attempt to control divergent behaviour through punishment, requiring conformation to social norms. Indigenous views of justice however work at restoring peace and equilibrium in the community by reconciling the wrongdoer to his/her own conscience with the individual or family that has been wronged (Archibald 2008, p. 102). Thus, understanding the relevance for Indigenous perspectives then requires "a re-valuation of forms of knowledge that are not derived from books" (Goody 1982, p. 201, qtd. in Kirkness and Barnhardt 1991) or Western institutionalised knowledge.

Additionally, the concept of value can differ between Indigenous and Western communities. Indigenous peoples are deeply impacted by nature, relationships, tradition and "valuables" that are passed down from elders in the form of stories, language and traditions. Stories are the basis for teaching and learning, and "life is in them for those who know how to ask and learn" (Cajete 1994, 41 qtd. in Archibald 2008 , p. 17). Value in modern Western society is institutionalised and primarily measured by economic or monetary terms through, e.g. gross domestic product or purchasing power parity and knowledge passed from education institutions. These perspectives are not necessarily "better" or "worse", but recognising the differences may help to bridge gaps between perspectives.

\subsection{Reciprocating}

Appreciating differences will help lead to the next inclusion value of reciprocating relationships (although different value systems can result in goals that are not easily reconciled with each other). This step can include accommodation on outcomes that meet the needs and interests of Indigenous peoples and not merely meeting legal or other or organisational obligations. One-sided consultation (often referred to by Fort McKay as "drive-by consultation") can reinforce unequal power dynamics if the consultation favours the powerful institution or organisation who enters into Indigenous communities with the objective of extracting information without listening or engaging in conversation or reciprocity. Kovach (2010) notes that ethical misconduct can occur when non-Indigenous researchers enter into Indigenous communities without cultural knowledge. She further also notes there are mutual benefits in developing a reciprocal relationship: "Because of the interconnection between all entities, seeking this information ought not to be extractive but reciprocal, to ensure an ecological and cosmological balance. Much insight comes to an individual inwardly and intuitively" (Kovach 2000). Kovach encourages a reflective and thoughtful approach to maintain a balance of give and take, a value that should be generally intuitive in our present day. 


\subsection{Responsibility}

Finally, "responsibility" is encouraged through participation for both Indigenous peoples and proponents. Responsibility is a form of accountability where proponents make efforts to accommodate Indigenous interests, for example, by creating more inclusive spaces for dialogue. When agreeing to be part of an engagement process, Indigenous peoples agree to participate and have their own responsibility to uphold their values. One important means of participation is through the oral tradition of storytelling. Kovach (2010) states that "The act of sharing through personal narrative, teaching story, and general conversation are methods by which each generation is accountable to the next in transmitting knowledge". When non-Indigenous parties are invited to listen to stories, there is an "implication that the listener is or becomes a member of the community" (Archibald 2008, p. 26). Inclusion also requires responsible use of the stories told, that is, to accurately reflect the knowledge shared through stories.

From the Western perspective, engagement and consultation are a means of creating a dialogue between two parties usually occurring within the context of conversations in meetings, workshops and interviews. Storytelling, therefore, can be a medium that unifies Indigenous world views and Western methods of gathering knowledge for research (Thomas 2005; Wilson 2001).

\section{Framework}

As indicated earlier in the chapter, consultation is a prior requirement when developing resources on treaty land, but Indigenous inputs from the consultation do not typically influence the outcomes, and this often leads to litigation. Consultation on its own is not sufficient, and the inclusion of Indigenous values is needed to gain consensus. Consensus should be achieved at each stage of the engagement process before moving on to the next stage. A criticism can be that consensus building prolongs the engagement processes. But ignoring or bypassing Indigenous right holders can potentially lead to even longer delays if the litigation route is taken. This can potentially jeopardise the entire projects (as discussed earlier).

In Fig. 1, we present a generic engagement process that focuses on step-by-step consensus building through consultation and inclusion based on the 4Rs. The consensus-building engagement process (CBEP) is broadly based on existing consultation processes indicated in the Alberta government duty to consult (Government of Alberta 2016b) and Fort McKay Sustainability Department consultation process (Fort McKay Sustainability Department 2012). The CBEP is shown as a cyclical process with five stages intended to support decision-making processes that impact Indigenous communities, particularly in resource development projects. For instance, the framing can be applied in oil sand development projects to support the consultation process when exploring the impacts of the project on Indigenous communities. 


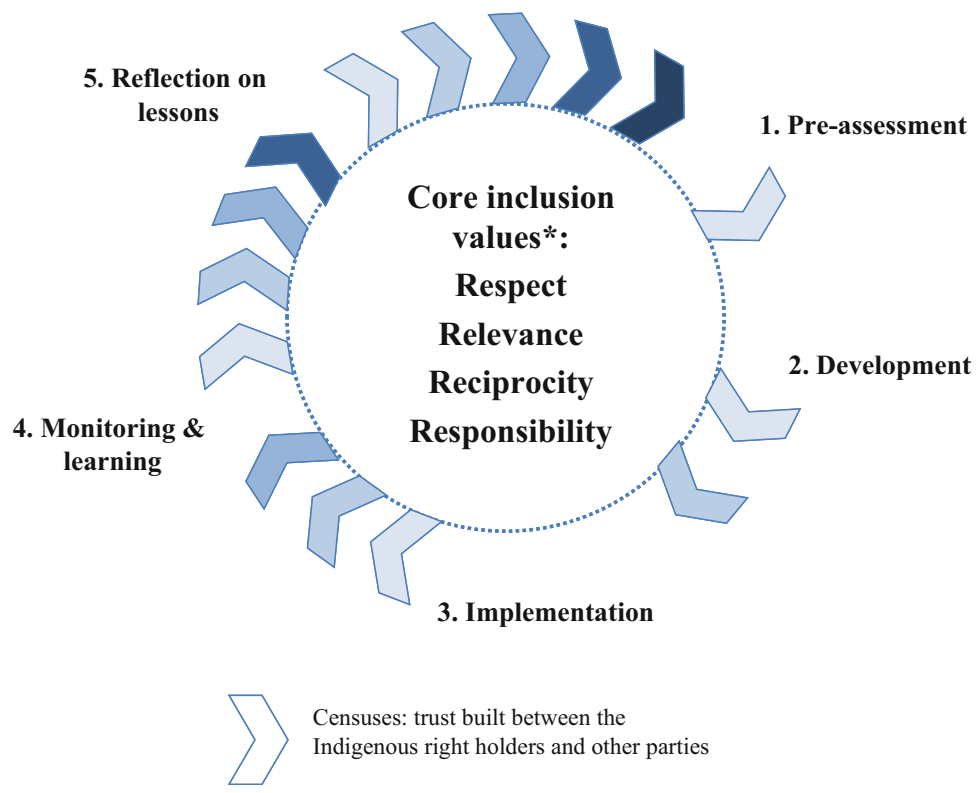

Fig. 1 Consensus-building engagement process. Source: Authors; 4Rs from Kirkness and Barnhardt (2001)

In between the CBEP stages, arrows represent steps needed to build up trust among parties during the consultation process. Effectively, the Indigenous community has veto power in each stage, as consensus is required before moving to the next step. Although consensus may prolong the entire engagement process, we argue that addressing the issues of concern within a respectful space defined by the Indigenous community and other parties is more constructive for building long-term relationships. Concerns can also be addressed through court but as stated earlier is costly for all sides involved. Consensus building will also help build trust in the long run between all parties involved and can further support future decision-making processes.

In describing the framework, we will define non-Indigenous peoples who wish to engage in a dialogue with the Indigenous community as "interested parties". Interested parties can include businesses (proponents), government, researchers or any other non-Indigenous community members. The Indigenous community is the community that will be affected by the interested party's actions, whether it is to meet the legal requirement of consultation or for research purposes.

The circle in the framework represents Indigenous ways of knowledge, cultural traditions and context of the community and reflects the holism or interrelatedness of the intellectual, spiritual, emotional and physical aspects of life. The circle is the core element of the engagement process and represents balance, inclusion, continuity and equality. Western processes and ways of knowledge are introduced and revolve around the circle, which signifies the Indigenous ways of knowledge. When seeking 
consultation, interested parties enter into the Indigenous community. This explicitly recognises that non-Indigenous perspectives need to respect Indigenous viewpoints. This potentially shifts the power dynamics away from interested parties, who are dependent on Indigenous peoples' consent and goodwill to achieve their desired outcomes. Consensus is gained step by step, with mutual trust as the building blocks of the engagement process. With time, greater trust is gained, and towards the end of the interaction, all participants can gain from the relationship established.

We acknowledge the differences across the many groups of Indigenous peoples in Canada and worldwide and recognise that there are a wide range of cultures, traditions, values and interests. We aim to present a framing with a central position of consulting Indigenous peoples to understand and include their interests and knowledge in shaping future pathways. We also acknowledge the efforts from the Canadian government and industries to involve consultation as part of the decisionmaking process but argue that much more, meaningful efforts need to be made to actively include Indigenous values, interests and rights through consensus building in order to truly accommodate the needs and interests of Indigenous communities and meet the spirit of UNDRIP.

The consensus-building engagement process (CBEP) framework is not intended to be an all-encompassing prescriptive engagement guideline for parties interested in initiating engagement with an Indigenous community. Rather, the framework intends to encourage a reflective engagement process that is codeveloped by the Indigenous right holders and interested parties in order to come to a consensus on decisions such as developing resources impacting Indigenous communities. The outcomes of the reflective engagement process should be mutually beneficial for the Indigenous community and the interested parties. We recognise each engagement process will differ based on the unique context. The CBEP framing broadly highlights key stages that can be generically considered in engagement processes that include (1) pre-assessment, (2) development, (3) implementation, (4) monitoring and learning and (5) reflection. The phases may not necessarily occur in a linear fashion, and there will likely be overlaps between phases or some phases may begin at the similar timeframes (e.g. implementation and monitoring/learning). The main idea is to recognise that each step is built from consensus gained through trust and the inclusions of the 4Rs.

\subsection{Pre-assessment}

In the initial stage before the project is underway, the issue at hand is raised by the party wishing to initiate the engagement process. A balance is needed between presenting the issues at hand (e.g. identifying low-carbon pathways) and setting the agenda (e.g. presenting set pathways and asking for validation). More time should be spent at this stage to gather resources by learning about Indigenous values, the community context, protocols and communication methods (Government of Canada 2015). Tools including stakeholder mapping methods (see Nikas et al. 
2017; Karakosta et al. 2011) can help to identify a broader stakeholder group through participatory approaches that may not be typically included in conventional consultation processes, for example, single parents, young members of the community and other groups that in number are not the dominant voice in the area. This technique can ensure a heterogenous representation can participate on the CBEP. The mapping method can also help to identify the interactions between stakeholders and make more explicate the important relationships that need greater attention.

Aside from drawing on existing literature which may provide general context, informal contacts can be made with Indigenous associations or independent Indigenous consultants in order to understand the specific protocols required for engagement and the (in)formal decision-making structure in the community. The informal consultation may help to identify problems early on that may be unknown to the parties and potentially surface later on. As a result of the consultation, the issue definition may need to be reassessed and the issues redefined to better reflect Indigenous viewpoints. Language and content of the issues may need to be adapted to consider Indigenous perspectives and use of words.

\subsection{Development: Listening and Conversations}

The development phase begins when the engagement is formally initiated and primarily consists of planning for the implementation phase where the full engagement takes place with the community. The community should be acknowledged and formally thanked for their participation and goodwill.

This planning phase provides a space for the Indigenous community and interested parties to discuss mutual interest before rolling out the full engagement process. The objective, motivations and outputs of the consultation need to be transparently discussed and the engagement timeframe agreed for the implementation phase. Not all community members may be involved in this phase depending on where the decision-making structures in the community may be focused. For instance, this phase might primarily include the project champions and other decision-makers in the community who may help to decide the form and nature of the engagement process.

Interested parties need to engage in respectful listening and respond responsibly to the insight gained in the planning process with the Indigenous communities. Listening will allow interested parties to gain valuable insights into understanding the communities' priorities and their knowledge base, which together motivate decisions. This sharing of views and interests can help to develop an implementation plan through consensus that is relevant to the community and also helps to meet the objectives of interested parties.

In terms of setting project meetings or deliverable dates, an important note is to allow for flexibility in delivery timeframes and formats. Western project management protocols often require rigid reporting templates and fixed timelines with limited flexibility (and often do not begin consultation early enough). But when 
engaging with Indigenous communities, the concept of reporting and time needs to be re-evaluated and expectations on both sides communicated clearly and respectfully. It may be preferable to initiate the engagement process earlier and adjustments made accordingly, if possible, to accommodate any reporting alternative and additional time needed. Once a consensus is agreed, the next step involves implementing the engagement plan. Additionally, the timing of the consultation needs to respect the timeframe of the communities by working around cultural practices, ceremonies and other activities. The location of the consultation is also important in terms of inclusion and fair representation. If the location is not thoughtfully arranged and considers the needs of Indigenous communities, it can lead to marginalisation at the spatial level or "social-spatial exclusion" (Trudeau and McMorran 2011; Kühn 2015). For instance, if members of the Indigenous communities are expected to travel far distances to participate in the consultation process, they will be isolated from their community support and may be more vulnerable to external pressures.

\subsection{Implementation: Inclusion and Accommodation}

The engagement process takes place during the implementation phase. This phase may contain multiple sub-steps and include a number of engagement rounds. Based on the first two phases, interested parties should have a relatively good idea about the context, protocols required and the interests of the Indigenous community. If interested parties are still uncertain about aspects of the implementation process, these concerns should be honestly and openly discussed with the Indigenous representative or community members to help with the learning process and in building trust.

\subsection{Monitoring and Learning: Responsibility and Accommodation}

The monitoring and learning process occurs when implementation phase is carried out (during and/or after). This phase is a continuous process where the engagement outcomes are being realised. It is essential during this phase that engagement outcomes are responsibly communicated to accurately reflect consultation outcomes. Changes may be needed in this phrase to correct a misunderstanding of results or to more accurately convey outcomes. This helps to ensure that reciprocity is maintained by following up on engagement results. Community members can be consulted on how frequent they would like the communication of results to occur and in what form. This step ensures accountability and responsibility when conveying results from the implementation stage and helps to assess if the results are relevant to Indigenous interests. 


\subsection{Reflection: Lessons}

This is the final phase of the engagement process, which can consist of presenting outcomes of the engagement process to the Indigenous community members and other relevant audiences (together or separately as mutually agreed). Project outputs codeveloped with the community should also be made fully available to the community, as they are also co-owned by the community. The explicit acknowledgement of the co-ownership of results shows respectful consideration of participation from all parties and acknowledges that results are an outcome of consensus building between Indigenous communities and interested parties.

\section{Conclusions}

The development and implementation of effective policies for climate change mitigation action require a true inclusion of the concerns, cultural values and interests of communities affected by these policies. To achieve true inclusion, an inclusive communication system can be followed throughout the engagement life cycle, considering the fundamental principles of the community as the core elements for consultation, participation and implementation. This approach is especially needed when the communities at risk of the negative impacts associated with resource development are conformed by Indigenous peoples. The fundamental principles of Indigenous knowledge not only play a role in communication and cultural exchange but also provide generation-long information of the local land and valuable perspectives on sustainability and climate change.

Indigenous world views emphasise the unity of the individual with the environment and all living things, and these values are aligned with sustainability and low-carbon futures. Meanwhile, modern economic Western paradigms perceive societal development primarily from an economic growth perspective. These different world views can increase the risks for climate change mitigation action at the government, industry and community level. Acknowledging the existence of different world views requires that more effective and collaborative methods of communication are needed to develop a true inclusive action plan. As an approach to achieving inclusion and reducing risks of negatives outcomes, a consensus-building engagement process (CBEP) was proposed with Indigenous values and interests as core elements.

In the CBEP, the Indigenous community essentially has veto power in the decisions made in each stage for the decision-making process (i.e. developing oil sand resources). Reaching consensus is necessary before moving forward to the subsequent steps as a means to ensure mutual understanding among the entities involved before a final decision is taken. Although it is advised to consider Indigenous knowledge and interests as a starting point, we acknowledge a total shift in the thought process of the parties is not yet possible since individuals (non-Indigenous) 
tend to rely on their own set of values in decision-making. However, we consider that by having the intention to place Indigenous knowledge and interests first, we can provide a framing to allow all parties to make more balanced analyses of both perspectives.

On the other hand, considering the resources and influence of government institutions and companies, it is not realistic (yet) to assume there will be an equal level of power for parties participating in an engagement process. Therefore, a way to mitigate the unequal power dynamics can be through inviting a neutral third party to oversee, facilitate and champion the process. The facilitator can be an expert that has knowledge and experience working with Indigenous communities. The thirdparty facilitator may improve communication and act as a mediator when needed. The government also needs to rethink its risk-averse approach by participating directly in the consultation in a meaningful way. This will allow for better communication between the government and Indigenous peoples, a relationship that has historically been difficult. However, cooperation is unavoidable if Canada wishes to seriously address climate change and sustainability and the impact and risks of resource development on Indigenous communities.

In addition to the consensus-building engagement process that considers local communities' interests and values, the equal inclusion of Indigenous communities in the decision-making process (e.g. including veto power) is essential to the development of a sustainable and legitimate low-carbon pathway. Additional studies are also needed to develop best corporate and government practices for inclusion to reduce the risks associated with resource development in communities and the environment. More Indigenous voices and perspectives are needed in the scientific climate change community, including IPCC reports, journal articles and other media sources, to disseminate values and concepts that balance socioeconomic needs and promote environmental stewardship relevant for the climate change mitigation needs of today and the future.

Canada, along with many high-emitting countries, can no longer continue to develop its high-carbon energy resources without facing risks of litigation and backlash not only from the Indigenous communities but from international pressures. The Paris Agreement and its objectives have changed the playing field, and countries must address climate change as well as consider the rights and interests of local communities, particularly Indigenous people who are impacted by risk related to climate change and mitigation action. Canada can lead in this area by setting a precedence for engaging in fair and effective consultation with Indigenous communities to address the complex problems of climate change.

\section{References}

Alexander, C., Bynum, N., Johnson, E., King, U., Mustonen, T., Neofotis, P., Oettlé, N., Rosenzweig, C., Sakakibara, C., Shadrin, V., Vicarelli, M., Waterhouse, J., \& Weeks, B. (2011). Linking indigenous and scientific knowledge of climate change. BioScience, 61(6), $477-484$. 
AMNH, American Museum of Natural History. (2008). Sustaining cultural and biological diversity in a rapidly changing world. In Sustaining cultural and biological diversity in a rapidly changing world: Lessons for global policy. New York City. Accessed from http://www. wennergren.org/history/sustaining-cultural-and-biological-diversity-rapidly-chaning-world-les sons-global-policy.

Archibald, J. A. (2008). Indigenous storywork: Educating the heart, mind, body, and spirit. Vancouver: UBC Press.

Baker, S. H. (2013). Why the IFC's free, prior, and informed consent policy doesn't matter (yet) to indigenous communities affected by development projects.

Baker, M. J., \& Westman, C. (2018). Extracting knowledge: Social science, environmental impact assessment, and Indigenous consultation in the oil sands of Alberta, Canada. The Extractive Industries and Society, 5(1), 144-153.

Boothe, P., \& Boudreault, F.-A. (2016). By the numbers: Canadian GHG emissions. Lawrence National Centre for Policy and Management. Accessed from http://www.ivey.uwo.ca/news/ news-ivey/2016/1/by-the-numbers-canadian-ghg-emissions/.

Cajete, G. (1994). Look to the mountain: An ecology of Indigenous education. Skyland, NC: Kivaki Press.

Calgary Chamber. (2015). The consultation conundrum: Examining aboriginal consultation in Alberta.

Daniel, R., Wright, T., \& Limited, D. (1980). Treaties of the Northwest, 1871-1930. In A history of native claims processes in Canada, 1867-1979 (p. 9). Ottawa: Department of Indian and Northern Affairs.

Dearden, P., \& Mitchell, B. (1998). Environmental change and challenge: A Canadian perspective. Toronto, ON: Oxford University Press.

Draper, D. (1998). Our environment: A Canadian perspective. Scarborough, ON: International Thomson.

Energy Resources Conservation Board, A. (2010). ST98-2010: Alberta's energy reserves 2009 and supply/demand outlook 2010-2019. Accessed from http://www.aer.ca/documents/sts/ST98/ st98_2010.pdf.

Environment Canada. (2017). Canadian economic sector provinces territories 1990-2015. Accessed from http://donnees.ec.gc.ca/data/substances/monitor/national-and-provincial-territo rial-greenhouse-gas-emission-tables/D-Tables-Canadian-Economic-Sector-Provinces-Terri tories/?lang=en.

Ermine, W. (2000). Aboriginal epistemology. In M. Battiste \& J. Barman (Eds.), First nation education in Canada: The circle unfolds (pp. 101-111). Vancouver, BC: UBC Press.

Ford, J. D., et al. (2016). Including Indigenous knowledge and experience in IPCC assessment reports. Nature Climate Change, 6(4), 349-353. https://doi.org/10.1038/nclimate2954.

Fort McKay Sustainability Department. (2012). Consultation process - Proponent guide.

Government of Alberta. (2013). The Government of Alberta's policy on consultation with first nations on land and natural resource management, 2013.

Government of Alberta. (2016a). The Government of Alberta's guidelines on consultation with Metis settlements on land and natural resource management 2016.

Government of Alberta. (2016b). Oil Sands Emissions Limit Act, Statutes of Alberta, 2016 (p. Chapter O-7.5). Accessed from http://www.qp.alberta.ca/1266.cfm?page=O07p5.cfm\&leg_ type $=$ Acts\&isbncln $=9780779794768$.

Government of Canada. (1982). Rights of the aboriginal peoples of Canada. In Part II. Constitution Act, 1982. Accessed from http://laws-lois.justice.gc.ca/eng/Const/page-16.html.

Government of Canada. (2015). First nations communications toolkit.

Hart, M. A. (2010). Indigenous worldviews, knowledge, and research: The development of an indigenous research paradigm. Journal of Indigenous Voices in Social Work, 1(1), 1-16.

Henton, D. (2016, April 26). Fort McKay First Nation sues Alberta over energy development. Calgary Herald. Accessed from http://calgaryherald.com/business/energy/fort-mckay-firstnation-sues-alberta-over-energy-development. 
Indigenous and Northern Affairs, C. (2008). Treaty-making in Canada. Accessed from http://www. aadnc-aandc.gc.ca/eng/1100100028574/1100100028578.

Indigenous and Northern Affairs, C. (2009). Treaty research report - Treaty Eight (1899). Accessed from http://www.aadnc-aandc.gc.ca/eng/1100100028809/1100100028811.

Indigenous and Northern Affairs, C. (2011). Aboriginal consultation and accommodation Updated guidelines for Federal officials to fulfil the duty to consult.

Joseph, B. (2017). Aboriginal rights, title, and the duty to consult. Port Coquitlam.

Karakosta, C., Doukas, H., \& Psarras, J. (2011). CDM sustainable technology transfer grounded in participatory in-country processes in Israel. International Journal of Sustainable Society, 3(3), 225-242.

Kirkness, V. J., \& Barnhardt, R. (1991). First nations and higher education. Journal of American Indian Education, 30(3), 1-18.

Kirkness, V. J., \& Barnhardt, R. (2001). First nations and higher education: The four R's - respect, relevance, reciprocity, responsibility. In R. Hayoe \& J. Pan (Eds.), Knowledge across cultures: A contribution to dialogue among civilizations. Hong Kong: Comparative Education Research Centre, The University of Hong Kong.

Kovach, M. E. (2000). Indigenous methodologies: Characteristics, conversations, and contexts. Toronto: University of Toronto Press.

Kovach, M. (2010). Conversational method in indigenous research. First Peoples Child \& Family Review, 5(1), 40-48.

Kühn, M. (2015). Peripheralization: Theoretical concepts explaining socio-spatial inequalities. European Planning Studies, 23(2), 367-378.

Laidlaw, D., \& Passelac-Ross, M. (2014, March). Alberta First Nations consultation \& accommodation handbook (p. 122). Accessed from http://prism.ucalgary.ca/bitstream/1880/50216/1/ ConsultationHandbookOP44.pdf.

Leach, A., et al. (2015). Executive summary. CLIMATE LEADERSHIP. Report to Minister. Alberta Minister of Environment and Parks. Accessed from http://www.alberta.ca/climate-leadershipplan.aspx.

Lertzman, D., \& Vredenburg, H. (2015). Indigenous peoples, resource extraction and sustainable development: An ethical approach. Journal of Business Ethics, 56(239), 239-254.

McGregor and Debroah. (2004). Traditional ecological knowledge and sustainable development: Towards coexistence. In M. Blaser, H. A. Feit, \& G. McRae (Eds.), In the way of development: Indigenous peoples, life projects, and globalization (pp. 72-91).

Mustonen, T. (2005). Stories of the Raven - Snowchange 2005 Conference Report Anchorage, Alaska, USA.

Natural Resources Canada, N. R. C. (2016). Energy fact book. Accessed from https://www.nrcan. gc.ca/sites/www.nrcan.gc.ca/files/energy/pdf/EnergyFactBook_2016_17_En.pdf.

Nikas, A., et al. (2017). Managing stakeholder knowledge for the evaluation of innovation systems in the face of climate change. Journal of Knowledge Management, 21(5), 1013-1034.

Pillay, N. (2013). Free, prior and informed consent of indigenous peoples. Accessed from http:// www.ohchr.org/Documents/Issues/IPeoples/FreePriorandInformedConsent.pdf.

Pryce, P. (1992). The manipulation of culture and history: A critique of two expert witnesses. Native Studies Review, 8(1), 35-46.

Scollon, R., \& Scollon, S. (1981). Narrative literacy and face in interethnic communication. Norwood, NJ: Ablex Publishing Corporation.

Simpson, L. (2000). Anishinaabe ways of knowing. In J. Oakes, R. Riew, S. Koolage, L. Simpson, \& N. Schuster (Eds.), Aboriginal health, identity and resources (pp. 165-185). Winnipeg, MB: Native Studies Press.

Symon, C., Arris, L., \& Heal, B. (Eds.). (2005). Arctic climate impact assessment. Cambridge University Press. Accessed from http://caid.ca/ACIA.html.

The Constitution Act. (1982). Schedule B to the Canada Act 1982 (UK), c 11.

Thomas, R. (2005). Honoring the oral traditions of my ancestors through story-telling. In S. Strega \& L. Brown (Eds.), Research as resistance (pp. 237-254). Toronto: Canadian Scholars' Press. 
TORYS. (2016). Free prior and informed consent in Canada. Towards a new relationship with indigenous peoples.

Trudeau, D., \& McMorran, C. (2011). The geographies of marginalization. In A companion to social geography (pp. 437-453). Wiley-Blackwell.

Truth and Reconciliation Commission. (2015). Truth and reconciliation commission: Calls to action.

UNFCCC, S. (2015). Canada intended nationally determined contributions (INDCs). United Nations Framework Convention on Climate Change.

UNFCCC, S. (2017). The Paris Agreement - Main page. Accessed October 5, 2017, from http:// unfccc.int/paris_agreement/items/9485.php.

United Nations. (2008). United Nations declaration on the rights of indigenous peoples.

University of Alberta Faculty of Native Studies. (2015). 'Indigenous Canada: Looking Forward/ Looking Back: Worldview'. Module 1. Edmonton: University of Alberta.

Weber, B. (2016, April 27). Alberta to repeal Prentice's First Nations consultation law Bill. $C B C$ News. Accessed from http://www.cbc.ca/news/canada/edmonton/alberta-to-repeal-prentice-sfirst-nations-consultation-law-1.3555973.

Wilson, S. (2001). What is Indigenous research methodology? Canadian Journal of Native Education, 25(2), 175-179.

Wood Buffalo Environmental Association. (2010). Traditional ecological knowledge/Berry Monitoring Project Factsheet.

Wood Buffalo Environmental Association. (2017). Wood Buffalo Environmental Association I Traditional knowledge. Accessed from http://www.wbea.org/traditional-knowledge.

World Resources Institute, W. R. I. (2016). CAIT climate data explorer - Historical emissions. Accessed from http://cait.wri.org/historical/, Environment Canada and World Bank Population data?indicator[]=Total GHG Emissions Excluding Land-Use Change and Forestry\&indicator []$=$ Total GHG Emissions Including Land-Use Change and Forestry\&year[]= 2012\&sortIdx $=$ NaN\&chartT.

Open Access This chapter is licensed under the terms of the Creative Commons Attribution 4.0 International License (http://creativecommons.org/licenses/by/4.0/), which permits use, sharing, adaptation, distribution and reproduction in any medium or format, as long as you give appropriate credit to the original author(s) and the source, provide a link to the Creative Commons license and indicate if changes were made.

The images or other third party material in this chapter are included in the chapter's Creative Commons license, unless indicated otherwise in a credit line to the material. If material is not included in the chapter's Creative Commons license and your intended use is not permitted by statutory regulation or exceeds the permitted use, you will need to obtain permission directly from the copyright holder.

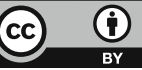

